OPEN ACCESS

Edited by:

Ying Wang,

Shanghai Institute of Nutrition and Health (CAS), China

Reviewed by: Yu Wang,

Shanghai Institute of Nutrition and Health (CAS), China

Menghui Jiang,

Qingdao University, China

*Correspondence:

Ruiming Rong

rong.ruiming@zs-hospital.sh.cn

${ }^{t}$ These authors have contributed equally to this work

Specialty section:

This article was submitted to Molecular Innate Immunity, a section of the journal

Frontiers in Immunology

Received: 22 March 2021 Accepted: 10 May 2021 Published: 28 May 2021

Citation:

Luo Y, Guo J, Zhang P, Cheuk YC, Jiang $Y$, Wang J, Xu S and Rong $R$ (2021) Mesenchymal Stem Cell Protects Injured Renal Tubular Epithelial Cells by Regulating mTOR-Mediated Th17/Treg Axis.

Front. Immunol. 12:684197. doi: 10.3389/fimmu.2021.684197

\section{Mesenchymal Stem Cell Protects Injured Renal Tubular Epithelial Cells by Regulating mTOR-Mediated Th17/Treg Axis}

\author{
Yongsheng Luo ${ }^{1,2 \dagger}$, Jingjing Guo ${ }^{1,2 \dagger}$, Pingbao Zhang ${ }^{12 \dagger}$, Yin Celeste Cheuk ${ }^{1,2}$, \\ Yamei Jiang ${ }^{1,2}$, Jiyan Wang ${ }^{2,3}$, Shihao $\mathrm{Xu}^{1,2}$ and Ruiming Rong ${ }^{1,2 *}$ \\ ${ }^{1}$ Department of Urology, Zhongshan Hospital, Fudan University, Shanghai, China, ${ }^{2}$ Shanghai Key Laboratory of Organ \\ Transplantation, Shanghai, China, ${ }^{3}$ Shanghai Medical College, Fudan University, Shanghai, China
}

The increase in Thelper 17 cell (Th17)-mediated pro-inflammatory response and decrease in regulatory $\mathrm{T}$ cell (Treg)-mediated anti-inflammatory effect aggravate renal tubular epithelial cell (RTEC) injury. However, increasing evidence indicated that mesenchymal stem cell (MSC) possessed the ability to control the imbalance between Th17 and Treg. Given that Th17 and Treg are derived from a common CD4 ${ }^{+} \mathrm{T}$ cell precursor, we summarize the current knowledge of MSC-mediated inhibition of the mammalian target of rapamycin (mTOR), which is a master regulator of $\mathrm{CD} 4^{+} \mathrm{T}$ cell polarization. During $\mathrm{CD} 4^{+}$ T cell differentiation, mTOR signaling mediates Th17 and Treg differentiation via hypoxiainducible factor- $1 \alpha(\mathrm{HIF}-1 \alpha)$-dependent metabolic regulation and signaling pathway, as well as mTOR-mediated phosphorylation of signal transducer and activator of transcription (STAT) 3 and 5. Through interfering with mTOR signaling, MSC restrains $\mathrm{CD}^{+} \mathrm{T}$ cell differentiation into Th17, but in turn promotes Treg generation. Thus, this review indicates that MSC-mediated Th17-to-Treg polarization is expected to act as new immunotherapy for kidney injury.

Keywords: mesenchymal stem cell, kidney injury, regulatory T cell, T helper 17 cell, mTOR

\section{INTRODUCTION}

Renal tubular epithelial cell (RTEC) injury due to ischemia-reperfusion injury (IRI), nephrotoxicity and other causes lead to a rapid decline in renal function and over-activated inflammatory immune response. If the inflammatory damage to RTEC was not controlled timely, a continuous renal injury would result in renal fibrosis and failure (1-3). Unfortunately, current pharmacological interventions have failed to prevent intrarenal inflammatory cascade. However, increasing studies showed that a diverse mesenchymal stem cell (MSC) population could form a balanced inflammatory microenvironment and protect injured RTEC by regulating mammalian target of 
rapamycin (mTOR)-mediated balance between proinflammatory $\mathrm{T}$ helper 17 cell (Th17) and anti-inflammatory regulatory $\mathrm{T}$ cell (Treg) (4-7).

In this review, we will introduce the imbalance between Th17 and Treg in RTEC injury, subsequently discuss MSC control for Th17 and Treg balance, and ultimately integrate current major mechanisms of MSC regulation on mTOR-mediated Th17 and Treg differentiation.

\section{THE IMBALANCE AND FUNCTIONS OF TH17 AND TREG IN RTEC INJURY}

Th17 characterized by the expression of specific transcription factor RAR-related receptor $\gamma$ thymus isoform (ROR $\gamma \mathrm{t}$ ) plays a vital role in RTEC damage by producing IL-17 and other proinflammatory cytokines $(8,9)$. However, through the specific immunoregulatory functions, Treg that express the transcription factor forkhead box protein P3 (Foxp3) can inhibit Th17mediated inflammatory response, promote inhibitory cytokine secretion, and ultimately protect renal injury $(5,6,10)$.

\section{Th17-Dominant Kidney Damage}

Numerous studies indicated that Th17 participated as the main kidney infiltrating inflammatory mediator in RTEC injury due to ureteral obstruction, acute kidney injury, chronic kidney disease, etc (11-14). Moreover, some studies reported that the Th17 number and Th17/Treg ratio were positively associated with the level of renal injury. Meanwhile, Th17 deficient mice due to IL-17 or RORyt null significantly alleviated RTEC injury (15).

The predominant Th17 exerted a robust pro-inflammatory response in renal injury via the expressions of IL-17 and C-Cmotif chemokine receptor (CCR) 6 (9, 16-18). For example, Kaneko et al. reported that Th17-secreting IL-17 bound to the corresponding receptor and promoted the expression of C-C motif chemokine ligand (CCL) 20, which attracted pro-inflammatory lymphocytes, dendritic cells, monocytes, and neutrophils to RTEC and ultimately led to immune-mediated damage to the kidney (9). Moreover, IL-17 was also found to increase CCL2 and IL-8 expressions in human proximal RTEC (19). Meanwhile, in obstructive renal injury, Th17 may contribute to the fibrotic transition from acute kidney injury to chronic kidney disease due to IL-17A expression $(11,12)$. In addition, some studies indicated that Th17 exerted distinct effector functions by necessarily migrating to target organs, which was mediated by chemokines [such as CCL20] and corresponding receptors [such as CCR6] $(16,19,20)$. Moreover, Th17 was reported to induce CCL20 expression in RTEC, promoting the recruitment of other leukocytes to the kidney (19).

\section{Treg-Weak Renoprotection}

A recent study of single-cell RNA-seq of renal immune cells showed that Treg in regenerating renal existed the high expression of tissue repair- and pro-angiogenesis-related genes. This finding suggested that Treg provided potential kidney protection from kidney damage (21). Indeed, Treg was reported to exert a key role in preventing kidney injury and facilitating renal repair (22-24). For instance, Treg can prevent inflammatory cell accumulation and promote anti-inflammatory M2-macrophage generation, which exerted a renoprotective function during acute or chronic renal injury $(5,10)$. In addition, some studies reported that Treg depletion in mice enhanced inflammatory response and aggravated kidney injury (25-28). Moreover, the deficiency of Foxp3 in Rag1 $^{-/}$mice also caused severe kidney damage (28). These studies indicated Treg renoprotection.

Unfortunately, Cao et al. reported that low percentages of Treg in intrarenal leucocytes existed in mice renal at $24 \mathrm{~h}$ after IRI (25). Moreover, Dong et al. also found decreased Treg number in patients with acute kidney injury (29). Meanwhile, increasing studies indicated that lower Treg infiltration, compared with Th17, existed in the injured kidney (30-32). Some studies also found that the adoptive transfer of Treg reduced pro-inflammatory IFN- $\gamma$ and TNF- $\alpha$ generation, improved kidney function, and relieved acute tubular necrosis after migration to the postischemic kidney (33-35). These transferred cells were also able to inhibit innate immune-related renal injury via switching ATP into adenosine mediated by CD73 on the surface of Treg. Subsequently, the adenosine bound to the $A_{2 a}$ receptor and then enhanced the expression of PD-1, which exerted a vital renoprotective effect during IRI $(34,36)$.

\section{THE BALANCE BETWEEN TH17 AND TREG CONTROLLED BY MSC}

MSC is a fibroblast-like cell population extracted from fat, bone marrow, umbilical cord, and other tissues, with an immune privilege due to low immunogenicity (8). Recent studies showed that the most intriguing role of MSC was the immunomodulatory effect on the $\mathrm{CD} 4^{+} \mathrm{T}$ cell polarization, with induction of Treg and suppression of Th17 differentiation $(9,37)$. For example, in an arthritis model, human MSC infusion could reduce Th17 number, promote Treg generation and enhance IL-10 production (38). Ghannam et al. reported that MSC induced a regulatory Th17 generation with ROR $\gamma t$ downregulation and FOXP3 upregulation, which suppressed $\mathrm{T}$ cell proliferation and alleviated inflammation (39). Therefore, MSC-mediated Th17-to-Treg polarization creates anti-inflammatory processes and then protects injured RTEC.

\section{The Enhancement of Treg Effect}

$\mathrm{Hu}$ et al. reported that MSC infusion increased Treg proportion in the renal and spleen, protecting the injured kidney $(40,41)$. Moreover, Casiraghi et al. found that transfer of MSC expanded Treg proportion in lymphoid organs and further prolonged kidney allograft survival (42). Similarly, autologous transfer of MSC to patients after kidney transplantation possessed the ability to generate Treg (43). Indeed, it was demonstrated that Treg depletion eliminated MSC protection for organ injury (44).

It is well established that Treg and Th17 derive from a common $\mathrm{CD}^{+} \mathrm{T}$ cell precursor, which offers the potential for MSC-mediated $\mathrm{CD}^{+}{ }^{+} \mathrm{T}$ cells differentiating into Treg but not Th17 (45). For instance, English et al. reported that $\mathrm{CD} 4^{+} \mathrm{T}$ cells and MSC coculture suppressed lymphocyte proliferation due to an increased Treg differentiation (46). Meanwhile, Liu et al. 
reported that the coculture of T cells and mice MSC showed a significant increase in Foxp3 expression and Treg proportion (47), which was similar to the human MSC coculture experiment (48). Moreover, both in vivo and in vitro, MSC favored Treg generation and their immunosuppressive function (49).

\section{The Attenuation of Th17 Effect}

Numerous studies indicated that the inhibition of Th17 and corresponding function could act as effective methods of protecting renal injury $(12,50-52)$. In vitro experiments from rat and human indicated that MSC possessed the ability to decrease Th17 generation from naive T cells and inhibit IL-17 and IL-22 secretion from Th17 $(39,53)$. Meanwhile, in vivo, the application of MSC suppressed EAE progress by reducing the secretion of IL-17 and IL-23 (54).

Furthermore, Th17 was reported to possess the ability to transdifferentiate into Foxp $3^{-} \mathrm{IL}-10^{+}$type 1 Treg (Tr1) with suppressive properties $(55,56)$. Moreover, MSC also was found to promote Foxp3 expression with increased IL-10 secretion, but suppress RORC expression with reduced IL-17 and IL-22 in differentiated Th17. Meanwhile, MSC stimulated by inflammatory cytokine showed a high CD54 expression, which contributed to the adhesion of Th17 to MSC and the induction of T cell with regulatory features (39). These findings suggest a new approach of treating injured RTEC by intervening pathogenic Th17 into suppressive Th17.

In addition, some studies indicated that Treg also possessed the ability to inhibit Th17-mediated kidney injury $(12,45,57$, 58). Particularly, recent studies reported a specialized Treg type 17 that colocalized with Th17 and exclusively inhibited Th17mediated effect via spatial interaction, IL-10 production, and CCR6 expression $(19,59)$.

\section{MSC-MEDIATED MTOR INHIBITION REGULATING TH17/TREG AXIS}

Mechanistically, MSC regulates the balance between Th17 and Treg predominantly via indoleamine 2, 3-dioxgenase (IDO) and TGF- $\beta$ secretions as well as other mechanisms, which mimic the rapamycin effect of inhibiting $\mathrm{mTOR}$, including $\mathrm{mTOR}$ complex 1 (mTORC1) and 2 (mTORC2) (8, 9, 60-65). Accumulating evidence indicates that $\mathrm{mTOR}$, a serine/threonine kinase, acts as a key regulator of metabolic programmers and signaling pathways in $\mathrm{CD}^{+} \mathrm{T}$ cell differentiation $(62,66,67)$. For example, stimulating mTOR activation in $\mathrm{CD}^{+}{ }^{+} \mathrm{T}$ cell drove glycolytic metabolism and promoted ROR $\gamma$ t expression. However, MSC-mediated mTOR downregulation during $\mathrm{CD}^{+}$ $\mathrm{T}$ cell differentiation induced Treg generation by fostering oxidative metabolism and Foxp3 transcription. Thus, MSCmediated mTOR inhibition in $\mathrm{CD}^{+} \mathrm{T}$ cell promotes Th17-toTreg polarization, conducive to protecting injured $\operatorname{RTEC~}(5,6,8$, 62-64) (Figure 1).

\section{MSC Inhibition on mTOR Signaling}

Several studies showed that MSC-producing IDO could inhibit Th17 differentiation, induce Treg generation, and subsequently prevent renal injury $(9,61,64)$. IDO is the main enzyme for promoting tryptophan catabolism into kynurenine. However, tryptophan was reported to possess the ability to activate the Rag complex, which recruited and linked mTORC1 to Rheb on the lysosomes. Subsequently, mTORC1 was activated due to the spatial regulation of Rheb and Rag (68-70). These findings may explain the phenomenon that IDO-mediated tryptophan exhaustion caused mTORC1 (as a nutrient sensor) inhibition, which further suppressed Th17 number and function but promoted Treg generation. Moreover, IDO depletion or tryptophan supplement reversed the effects $(9,61,62,64)$.

In addition to IDO, TGF- $\beta$ secreted by MSC plays a role for inducing Treg generation due to mTOR inhibition $(8,61,63)$. Priyadharshini et al. found that exposure of Treg to TGF- $\beta$ repressed S6 and Akt phosphorylation targeting mTORC1 and mTORC2, respectively. Moreover, TGF- $\beta$ reprogrammed Treg metabolism by inhibiting PI3K-mediated mTOR signaling (63). These results are in line with the report that Smad3 phosphorylation mediated by the interaction between TGF- $\beta$ / TGF- $\beta$ receptor limited $\mathrm{CD}^{+}{ }^{+} \mathrm{T}$ cell proliferation and inhibited classic PI3K/Akt/mTOR pathway, which resembled rapamycin inhibition of mTOR signaling (65). Moreover, in vitro, the stimulation of TGF- $\beta$ altogether with all-trans retinoic acid promoted the expression of a set of microRNAs such as microRNA-15b/16, which inhibited Akt/mTOR signaling and further induced Treg generation $(71,72)$.

Additionally, Yoo et al. demonstrated that MSC suppressed CD25 expression on the surface of $\mathrm{T}$ cells via increased liver kinase B1 and AMP-activated protein kinase phosphorylation induced by low adenosine triphosphate (ATP) concentration (66). Liver kinase B1, a serine/threonine kinase, can increase phosphorylation of AMP-activated protein kinase and then inhibit mTORC1 signaling, which ultimately reduces inflammatory cytokine secretion in T cells $(60,66)$.

\section{mTOR-Mediated Th17/Treg Axis}

Increasing studies showed that mTOR-low populations of $\mathrm{CD} 4^{+} \mathrm{T}$ cells with increased oxidative phosphorylation were likely to become Treg with high signal transducer and activator of transcription (STAT) 5 and Foxp3 expression, while mTOR-high populations with enhanced hypoxia-inducible factor-1 $\alpha$ (HIF-1 $\alpha)$-mediated glycolysis were enriched for Th17 with high STAT3 and ROR $\gamma t$ expression $(22,73,74)$. Moreover, the transfer of Treg pretreated by pharmacological mTOR inhibition to kidney injury mice following by IRI can improve the renal function recovery and reduce kidney fibrosis due to enhanced immunoregulatory effect of Treg (75). These studies indicated that mTOR inhibition played a vital role in renal protection by promoting Treg but not Th17 differentiation, which involved mTOR-dependent energy metabolism and protein translation networks.

\section{mTOR/HIF-1 $\alpha$-Mediated Metabolic Reprogramming}

With $\mathrm{CD} 4^{+} \mathrm{T}$ cell activation, some glycolytic molecules, such as glyceraldehyde-3-phosphate dehydrogenase, lactate dehydrogenase and glucose transporters were upregulated to promote glucose uptake due to the increased bioenergetic demands (66). The process can be regulated by mTOR-mediated signaling, such as the transcription 
A

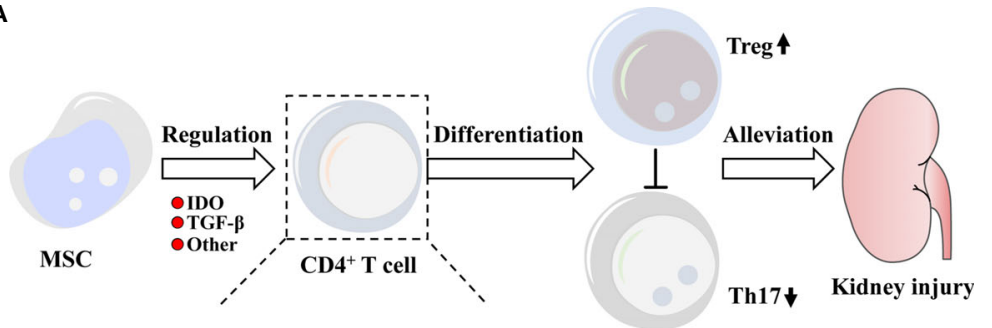

B

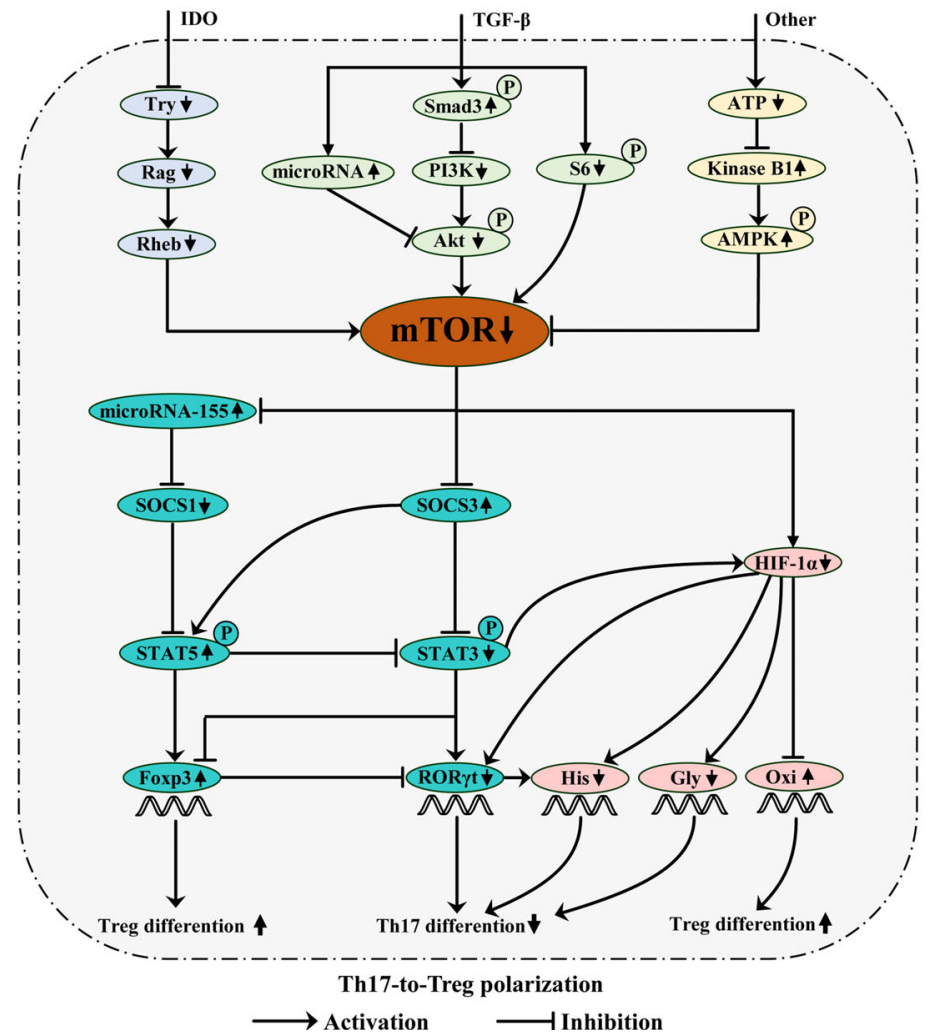

FIGURE 1 | Mesenchymal stem cell (MSC) protects kidney injury via mTOR-mediated Th17-to-Treg polarization. (A) MSC inhibits mTOR signaling during CD4 ${ }^{+}$T cell differentiation via IDO and TGF- $\beta$ secretions as well as other mechanisms, which restrains Th17 differentiation, but promotes Treg generation. Consequently, MSC-mediated Th17-to-Treg polarization alleviates kidney injury. (B) TGF- $\beta$ phosphorylates Smad3, which inhibits PI3K/Akt/mTOR pathway. TGF- $\beta$ also inhibits S6mediated mTOR signaling. Moreover, TGF- $\beta$ promotes microRNA expression, which can inhibit Akt/mTOR pathway. IDO can deplete tryptophan (Try), which results in mTOR inhibition mediated by the Rag and following Rheb. Additionally, MSC-mediated low ATP concentration increases kinase B1, subsequently phosphorylates AMPK, ultimately inhibits mTOR signaling. However, mTOR signaling can inhibit microRNA-155 and SOCS3 expression, but promote HIF-1 $\alpha$ generation. Briefly, microRNA-155 inhibits SOCS1 expression, which can restrain STAT5 phosphorylation. The phosphorylation of STAT5 not only restrains STAT3 phosphorylation, but also upregulates Foxp3 expression, which promotes Treg differentiation. SOCS3 can promote STAT5 phosphorylation, but inhibit STAT3-mediated HIF-1 $\alpha$ and ROR $\gamma$ t expression, which ultimately reduces Th17 differentiation. Moreover, STAT3 possesses the ability to inhibit Foxp3 expression. HIF-1 $\alpha$ can promote ROR $\gamma t$ expression and increase histone acetylation (His) with ROR $\gamma$ t collaboration, which possesses the ability to induce Th17 differentiation. Meanwhile, HIF-1 $\alpha$ inhibition can promote Treg but not Th17 differentiation by mediating glycolysis (Gly) switching into the oxidative phosphorylation (Oxi).

factor HIF-1 $\alpha$ expression (76). For example, mTOR was reported to promote STAT3 activation, which increased HIF-1 $\alpha$ expression via direct binding of STAT3 to the HIF-1 $\alpha$ gene promoter region (45, 62). Subsequently, increased HIF-1 $\alpha$ can mediate oxidative phosphorylation switching into aerobic glycolysis by targeting glycolytic genes such as glycolytic enzymes hexokinase 2, monocarboxylic acid transporter member 4 , and glucose transporter 1, which are vital for Th17 differentiation and IL-17 expression $(22,62)$. Consequently, HIF-1 $\alpha$-mediated glycolytic molecules act as main metabolic checkpoints to regulate $\mathrm{CD} 4^{+} \mathrm{T}$ cell polarization. For instance, HIF-1 $\alpha$ deficiency in $\mathrm{CD} 4^{+} \mathrm{T}$ cells resulted in less Th17 and IL-17 generations by diminishing glycolytic molecule expression $(22,45,62)$. In addition, the glucose analogue 2deoxyglucose was also reported to promote Treg differentiation but dampen the generation of Th17 during $\mathrm{CD} 4^{+} \mathrm{T}$ cell polarization by inhibiting key glycolytic molecules (22). Therefore, HIF-1 $\alpha$ dependent metabolic reprogramming mediated by mTOR signaling distinguishes the lineage decisions between Treg and Th17. 


\section{mTOR/HIF-1 $\alpha$-Mediated Signaling Pathway}

In addition to metabolic regulation, mTOR-mediated HIF- $1 \alpha$ also directly binds to ROR $\gamma t$ gene promoter region and subsequently promotes ROR $\gamma$ t transcription. Moreover, HIF- $1 \alpha$ with ROR $\gamma t$ collaboration activates p300-mediated histone acetyltransferase, which increases histone acetylation, opens up the chromatin structure, and ultimately facilitates Th17 differentiation $(45,77)$. Additionally, HIF-1 $\alpha$ was reported to activate the process that promoted the degradation of Foxp3, which inhibited the differentiation of Treg. Foxp3 degradation may explain that Foxp ${ }^{+}$ROR $\gamma t^{+}$Treg/TH17 precursors committed to the differentiation of Th17 by diminishing Foxp3 transcription (45). Moreover, HIF- $1 \alpha$ could drive the IL-23 receptor upregulation, vital for IL-17 and Th17 generation (22, 78). These results were in line with the report that HIF-1 $\alpha$ has high expression during the differentiation of Th17, while Treg showed a low level of HIF-1 $\alpha$ (26). Correspondingly, HIF- $1 \alpha$ absence mediated by mTOR inhibition impaired Th17 differentiation as well as IL-17 and IL-23 receptor expressions, but upregulated Foxp3 expression $(22,79)$. Meanwhile, Foxp3 upregulation antagonizes ROR $\gamma$ t expression and Th17 generation. Furthermore, Shi et al. also indicated that Ctla4 and Gpr83 molecules on the surface of Treg were upregulated due to HIF$1 \alpha$ absence (22). Therefore, mTOR-mediated HIF- $1 \alpha$ signaling would be expected to act as a key regulator of $\mathrm{CD}^{+} \mathrm{T}$ cell polarization.

\section{mTOR/STATs-Mediated Signaling Pathway}

Several studies showed that mTORC1 could activate STAT3 by inhibiting the suppressor of cytokine signaling (SOCS) 3 expression, which could repress STAT3 phosphorylation or induce proteasomal degradation of STAT3 $(76,80,81)$. Moreover, mTORC1 inhibited STAT5 activation by downregulating microRNA-155, an inhibitor of the SOCS1 (82-84). Similarly, mTORC1 inhibition was reported to increase the phosphorylation of STAT5 by inhibiting SOCS3 expression $(76,85)$.

Accumulating studies showed that STAT3 induced ROR $\gamma$ t and IL-17 expressions, while the deficiency of STAT3 impaired the expressions of ROR $\gamma t$ and IL-17, but increased Foxp3 expression $(62,76,86,87)$. However, through competition with STAT3, STAT5 could bind to IL-17a gene sites, subsequently modifying the IL-17 gene locus due to a decrease in histone-3 lysine- 4 trimethylation (IL-17 expression promoter) and increase in histone 3 lysine 27 trimethylation (IL-17 expression inhibition) $(62,87)$. Moreover, STAT5 activation was reported to promote the differentiation of Treg by upregulating the expression of Foxp3 $(76,88,89)$. Interestingly, several studies indicated that Foxp $3^{+} \mathrm{ROR} \gamma \mathrm{t}^{+}$
Treg/TH17 precursors under an anti-inflammatory environment (such as high TGF- $\beta$ levels without IL-6) showed a high Foxp3 expression that antagonized the binding of ROR $\gamma t$ to DNA via an exon 2-encoded sequence interaction, which inhibited IL-17 expression and further pushed $\mathrm{T}$ cell differentiation towards the Treg. Reversely, given that STAT3 activation stimulated by proinflammatory cytokines (such as IL-21 or IL- 6 with low TGF- $\beta$ levels) overcame Foxp3 antagonism of ROR $\gamma$ t, the precursors tended to IL-23 receptor upregulation and subsequently pushed T cell differentiation into Th17 $(45,90)$. Therefore, the activation of STAT3 or STAT5 mediated Th17 or Treg differentiation.

\section{CONCLUSIONS AND PERSPECTIVES}

Currently, MSC has been extensively reported as a promising therapy for renal injury due to its renoprotection for injured RTEC (91-93). However, the therapeutic effect of MSC was greatly weakened in the light of the fact that a majority of MSC were stuck in the lungs after adoptive transfer, with a small part reaching to the spleen, liver, renal, and other organs $(1,94)$. In view of a similar mechanism of mTOR inhibition, the transfer of MSC combination with rapamycin was also reported to exert immunosuppressive effect and protect injured RTEC to a higher degree (66). Although MSC-mediated Th17-to-Treg polarization mainly depended on mTOR inhibition, the immunoregulatory mechanism was complex and not fully understood. Therefore, a successful application would rely on deep exploration and further resolution of the unanswered question.

\section{AUTHOR CONTRIBUTIONS}

YL, JG, and PZ conceived the conception, performed the literature search and wrote the manuscript. YC, YJ, JW, and SX performed the literature search and participated in the writing. RR conceived the conception and revised the manuscript. All authors contributed to the article and approved the submitted version.

\section{FUNDING}

This work was supported by the National Key R\&D Program of China (2018YFA0107501) and National Natural Science Foundation of China (81770747 and 81970646).

\section{REFERENCES}

1. Fazekas B, Griffin MD. Mesenchymal Stromal Cell-Based Therapies for Acute Kidney Injury: Progress in the Last Decade. Kidney Int (2020) 97(6):1130-40. doi: 10.1016/j.kint.2019.12.019

2. Zilberman-Itskovich S, Efrati S. Mesenchymal Stromal Cell Uses for Acute Kidney Injury-Current Available Data and Future Perspectives: A Mini-Review. Front Immunol (2020) 11:1369. doi: 10.3389/fimmu. 2020.01369

3. Liu Y, Fang J. Mesenchymal Stem Cells as Therapeutic Agents and Novel Carriers for the Delivery of Candidate Genes in Acute Kidney Injury. Stem Cells Int (2020) 2020:8875554. doi: 10.1155/2020/8875554

4. Savio-Silva C, Soinski-Sousa PE, Balby-Rocha M, Lira AO, Rangel EB. Mesenchymal Stem Cell Therapy in Acute Kidney Injury (AKI): Review and Perspectives. Rev Assoc Med Bras (20201992) 66Suppl 1(Suppl 1):s45-54. doi: 10.1590/1806-9282.66.S1.45

5. Song T, Eirin A, Zhu X, Zhao Y, Krier JD, Tang H, et al. Mesenchymal Stem Cell-Derived Extracellular Vesicles Induce Regulatory T Cells to Ameliorate 
Chronic Kidney Injury. Hypertension (2020) 75(5):1223-32. doi: 10.1161/ HYPERTENSIONAHA.119.14546

6. Zhu Z, Han C, Xian S, Zhuang F, Ding F, Zhang W, et al. Placental Mesenchymal Stromal Cells (PMSCs) and PMSC-Derived Extracellular Vesicles (PMSC-EVs) Attenuated Renal Fibrosis in Rats With Unilateral Ureteral Obstruction (UUO) by Regulating CD4(+) T Cell Polarization. Stem Cells Int (2020) 2020:2685820. doi: 10.1155/2020/2685820

7. Shi Y, Wang Y, Li Q, Liu K, Hou J, Shao C, et al. Immunoregulatory Mechanisms of Mesenchymal Stem and Stromal Cells in Inflammatory Diseases. Nat Rev Nephrol (2018) 14(8):493-507. doi: 10.1038/s41581-0180023-5

8. Duffy MM, Ritter T, Ceredig R, Griffin MD. Mesenchymal Stem Cell Effects on T-Cell Effector Pathways. Stem Cell Res Ther (2011) 2(4):34. doi: 10.1186/ scrt75

9. Yang Y, Liu K, Chen Y, Gong Y, Liang Y. Indoleamine 2,3-Dioxygenase (IDO) Regulates Th17/Treg Immunity in Experimental Iga Nephropathy. Folia Biol (Praha) (2019) 65(2):101-8.

10. Sharma R, Kinsey GR. Regulatory T Cells in Acute and Chronic Kidney Diseases. Am J Physiol Renal Physiol (2018) 314(5):F679-98. doi: 10.1152/ ajprenal.00236.2017

11. Peng X, Xiao Z, Zhang J, Li Y, Dong Y, Du J, et al. IL-17A Produced by Both Gammadelta $\mathrm{T}$ and Th17 Cells Promotes Renal Fibrosis Via RANTESMediated Leukocyte Infiltration After Renal Obstruction. J Pathol (2015) 235(1):79-89. doi: 10.1002/path.4430

12. Mehrotra P, Patel JB, Ivancic CM, Collett JA, Basile DP. Th-17 Cell Activation in Response to High Salt Following Acute Kidney Injury Is Associated With Progressive Fibrosis and Attenuated by AT-1R Antagonism. Kidney Int (2015) 88(4):776-84. doi: 10.1038/ki.2015.200

13. Mehrotra P, Sturek M, Neyra JA, Basile DP. Calcium Channel Orail Promotes Lymphocyte IL-17 Expression and Progressive Kidney Injury. J Clin Invest (2019) 129(11):4951-61. doi: 10.1172/JCI126108

14. Pindjakova J, Hanley SA, Duffy MM, Sutton CE, Weidhofer GA, Miller MN, et al. Interleukin-1 Accounts for Intrarenal Th17 Cell Activation During Ureteral Obstruction. Kidney Int (2012) 81(4):379-90. doi: 10.1038/ ki.2011.348

15. Chan AJ, Alikhan MA, Odobasic D, Gan PY, Khouri MB, Steinmetz OM, et al. Innate IL-17A-Producing Leukocytes Promote Acute Kidney Injury Via Inflammasome and Toll-Like Receptor Activation. Am J Pathol (2014) 184 (5):1411-8. doi: 10.1016/j.ajpath.2014.01.023

16. Zhang YM, Liu XZ, Zhou XJ, Liu LJ, Shi SF, Hou P, et al. A Functional Variant rs3093023 in CCR6 is Associated With IgA Nephropathy by Regulating Th17 Cells in a North Han Chinese Population. Front Immunol (2021) 12:600598. doi: 10.3389/fimmu.2021.600598

17. Jang SG, Lee J, Hong SM, Kwok SK, Cho ML, Park SH, et al. Metformin Enhances the Immunomodulatory Potential of Adipose-Derived Mesenchymal Stem Cells Through STAT1 in an Animal Model of Lupus. Rheumatology (Oxford) (2020) 59(6):1426-38. doi: 10.1093/rheumatology/ kez631

18. Shanmugasundaram U, Bucsan AN, Ganatra SR, Ibegbu C, Quezada M, Blair RV, et al. Pulmonary Mycobacterium Tuberculosis Control Associates With CXCR3- and CCR6-expressing Antigen-Specific Th1 and Th17 Cell Recruitment. JCI Insight (2020) 5(14):e137858. doi: 10.1172/jci.insight.137858

19. Krebs CF, Schmidt T, Riedel JH, Panzer U. T Helper Type 17 Cells in Immune-Mediated Glomerular Disease. Nat Rev Nephrol (2017) 13(10):64759. doi: 10.1038/nrneph.2017.112

20. Koga T, Otomo K, Mizui M, Yoshida N, Umeda M, Ichinose K, et al. Calcium/ Calmodulin-Dependent Kinase IV Facilitates the Recruitment of Interleukin17-Producing Cells to Target Organs Through the CCR6/CCL20 Axis in Th17 Cell-Driven Inflammatory Diseases. Arthritis Rheumatol (2016) 68(8):1981-8. doi: 10.1002/art.39665

21. Do VDF, Lafont A, Beibel M, Martin K, Darribat K, Cuttat R, et al. Immune Cell Landscaping Reveals a Protective Role for Regulatory T Cells During Kidney Injury and Fibrosis. JCI Insight (2020) 5(3):e130651. doi: 10.1172/ jci.insight. 130651

22. Shi LZ, Wang R, Huang G, Vogel P, Neale G, Green DR, et al. HIFlalphaDependent Glycolytic Pathway Orchestrates a Metabolic Checkpoint for the Differentiation of TH17 and Treg Cells. J Exp Med (2011) 208(7):1367-76. doi: $10.1084 /$ jem.20110278
23. Ali R, Patel SN, Hussain T. Angiotensin Type 2 Receptor Activation Limits Kidney Injury During Early Phase and Induces Treg Cells During Late Phase of Renal Ischemia. Am J Physiol Renal Physiol (2021) 320(5):F814-25. doi: 10.1152/ajprenal.00507.2020

24. Sakai R, Ito M, Komai K, Iizuka-Koga M, Matsuo K, Nakayama T, et al. Kidney GATA3(+) Regulatory T Cells Play Roles in the Convalescence Stage After Antibody-Mediated Renal Injury. Cell Mol Immunol (2020) 18(5):124961. doi: 10.1038/s41423-020-00547-x

25. Jun C, Qingshu L, Ke W, Ping L, Jun D, Jie L, et al. Protective Effect of CXCR3 $(+) \mathrm{CD} 4(+) \mathrm{CD} 25(+)$ Foxp3(+) Regulatory $\mathrm{T}$ Cells in Renal IschemiaReperfusion Injury. Mediators Inflamm (2015) 2015:360973. doi: 10.1155/ 2015/360973

26. Kinsey GR, Sharma R, Huang L, Li L, Vergis AL, Ye H, et al. Regulatory T Cells Suppress Innate Immunity in Kidney Ischemia-Reperfusion Injury. J Am Soc Nephrol (2009) 20(8):1744-53. doi: 10.1681/ASN.2008111160

27. Jun C, Ke W, Qingshu L, Ping L, Jun D, Jie L, et al. Protective Effect of CD4(+) CD25(high)CD127(low) Regulatory T Cells in Renal Ischemia-Reperfusion Injury. Cell Immunol (2014) 289(1-2):106-11. doi: 10.1016/j.cellimm.2014.04.002

28. Kinsey GR, Sharma R, Huang L, Li L, Vergis AL, Ye H, et al. Regulatory T Cells Suppress Innate Immunity in Kidney Ischemia-Reperfusion Injury. J Am Soc Nephrol (2009b) 20(8):1744-53. doi: 10.1681/ASN.2008111160

29. Dong Q, Cai C, Gao F, Chen P, Gong W, Shen M, et al. Defective Treg Response in Acute Kidney Injury was Caused by a Reduction in TIM-3(+) Treg Cells. Immunol Invest (2019) 48(1):27-38. doi: 10.1080/ 08820139.2018.1493497

30. Wang Y, Zhang S, Zhang N, Feng M, Liang Z, Zhao X, et al. Reduced Activated Regulatory $\mathrm{T}$ Cells and Imbalance of Th17/activated Treg Cells Marks Renal Involvement in ANCA-Associated Vasculitis. Mol Immunol (2020) 118:19-29. doi: 10.1016/j.molimm.2019.11.010

31. Li Y, Shi Y, Huang Z, Bai Y, Niu Q, Cai B, et al. CNI Induced Th17/Treg Imbalance and Susceptibility to Renal Dysfunction in Renal Transplantation. Int Immunopharmacol (2011) 11(12):2033-8. doi: 10.1016/j.intimp.2011.08.015

32. Wang D, Zhang Z, Si Z, Yang Y, Li S, Xue Y, et al. Dapagliflozin Reverses the Imbalance of T Helper 17 and T Regulatory Cells by Inhibiting SGK1 in a Mouse Model of Diabetic Kidney Disease. FEBS Open Bio (2021) 11(5):1395405. doi: 10.1002/2211-5463.13147

33. Gandolfo MT, Jang HR, Bagnasco SM, Ko GJ, Agreda P, Satpute SR, et al. Foxp3+ Regulatory T Cells Participate in Repair of Ischemic Acute Kidney Injury. Kidney Int (2009) 76(7):717-29. doi: 10.1038/ki.2009.259

34. Kinsey GR, Sharma R, Okusa MD. Regulatory T Cells in AKI. J Am Soc Nephrol (2013) 24(11):1720-6. doi: 10.1681/ASN.2013050502

35. Heidari N, Abbasi-Kenarsari H, Namaki S, Baghaei K, Zali MR, Ghaffari KS, et al. Adipose-Derived Mesenchymal Stem Cell-Secreted Exosome Alleviates Dextran Sulfate Sodium-Induced Acute Colitis by Treg Cell Induction and Inflammatory Cytokine Reduction. J Cell Physiol (2021) 236(8):5906-20. doi: $10.1002 /$ jcp. 30275

36. Alikhan MA, Huynh M, Kitching AR, Ooi JD. Regulatory T Cells in Renal Disease. Clin Transl Immunol (2018) 7(1):e1004. doi: 10.1002/cti2.1004

37. Lee DK, Song SU. Immunomodulatory Mechanisms of Mesenchymal Stem Cells and Their Therapeutic Applications. Cell Immunol (2018) 326:68-76. doi: 10.1016/j.cellimm.2017.08.009

38. Gonzalez MA, Gonzalez-Rey E, Rico L, Buscher D, Delgado M. Treatment of Experimental Arthritis by Inducing Immune Tolerance With Human Adipose-Derived Mesenchymal Stem Cells. Arthritis Rheum (2009) 60 (4):1006-19. doi: 10.1002/art.24405

39. Ghannam S, Pene J, Moquet-Torcy G, Jorgensen C, Yssel H. Mesenchymal Stem Cells Inhibit Human Th17 Cell Differentiation and Function and Induce a T Regulatory Cell Phenotype. J Immunol (2010) 185(1):302-12. doi: 10.4049/jimmunol.0902007

40. Jang HR, Park JH, Kwon GY, Lee JE, Huh W, Jin HJ, et al. Effect of Preemptive Treatment With Human Umbilical Cord Blood-Derived Mesenchymal Stem Cells on the Development of Renal Ischemia-Reperfusion Injury in Mice. Am J Physiol Renal Physiol (2014) 307(10):F1149-61. doi: 10.1152/ajprenal. 00555.2013

41. Hu J, Zhang L, Wang N, Ding R, Cui S, Zhu F, et al. Mesenchymal Stem Cells Attenuate Ischemic Acute Kidney Injury by Inducing Regulatory T Cells Through Splenocyte Interactions. Kidney Int (2013) 84(3):521-31. doi: $10.1038 /$ ki.2013.114 
42. Casiraghi F, Azzollini N, Todeschini M, Cavinato RA, Cassis P, Solini S, et al. Localization of Mesenchymal Stromal Cells Dictates Their Immune or Proinflammatory Effects in Kidney Transplantation. Am J Transplant (2012) 12(9):2373-83. doi: 10.1111/j.1600-6143.2012.04115.x

43. Perico N, Casiraghi F, Introna M, Gotti E, Todeschini M, Cavinato RA, et al. Autologous Mesenchymal Stromal Cells and Kidney Transplantation: A Pilot Study of Safety and Clinical Feasibility. Clin J Am Soc Nephrol (2011) 6 (2):412-22. doi: 10.2215/CJN.04950610

44. Gazdic M, Markovic BS, Arsenijevic A, Jovicic N, Acovic A, Harrell CR, et al. Crosstalk Between Mesenchymal Stem Cells and T Regulatory Cells Is Crucially Important for the Attenuation of Acute Liver Injury. Liver Transpl (2018) 24(5):687-702. doi: 10.1002/lt.25049

45. Dang EV, Barbi J, Yang HY, Jinasena D, Yu H, Zheng Y, et al. Control of T(H) 17/T(reg) Balance by Hypoxia-Inducible Factor 1. Cell (2011) 146(5):772-84. doi: 10.1016/j.cell.2011.07.033

46. English K, Ryan JM, Tobin L, Murphy MJ, Barry FP, Mahon BP, et al. Cell Contact, Prostaglandin E(2) and Transforming Growth Factor Beta 1 Play Non-Redundant Roles in Human Mesenchymal Stem Cell Induction of CD4+ CD25(High) Forkhead Box P3+ Regulatory T Cells. Clin Exp Immunol (2009) 156(1):149-60. doi: 10.1111/j.1365-2249.2009.03874.x

47. Liu X, Ren S, Qu X, Ge C, Cheng K, Zhao RC, et al. Mesenchymal Stem Cells Inhibit Th17 Cells Differentiation Via IFN-Gamma-Mediated SOCS3 Activation. Immunol Res (2015) 61(3):219-29. doi: 10.1007/s12026-0148612-2

48. Casiraghi F, Perico N, Cortinovis M, Remuzzi G. Mesenchymal Stromal Cells in Renal Transplantation: Opportunities and Challenges. Nat Rev Nephrol (2016) 12(4):241-53. doi: 10.1038/nrneph.2016.7

49. Prevosto C, Zancolli M, Canevali P, Zocchi MR, Poggi A. Generation of CD4+ or CD8+ Regulatory T Cells Upon Mesenchymal Stem Cell-Lymphocyte Interaction. Haematologica (2007) 92(7):881-8. doi: 10.3324/haematol.11240

50. Motavalli R, Etemadi J, Soltani-Zangbar MS, Ardalan MR, Kahroba H, Roshangar L, et al. Altered Th17/Treg Ratio as a Possible Mechanism in Pathogenesis of Idiopathic Membranous Nephropathy. Cytokine (2021) 141:155452. doi: 10.1016/j.cyto.2021.155452

51. Marquez-Exposito L, Rodrigues-Diez RR, Rayego-Mateos S, Fierro-Fernandez M, Rodrigues-Diez R, Orejudo M, et al. Deletion of Delta-Like 1 Homologue Accelerates Renal Inflammation by Modulating the Th17 Immune Response. FASEB J (2021) 35(1):e21213. doi: 10.1096/fj.201903131R

52. Chen Y, Tao T, Wang W, Yang B, Cha X. Dihydroartemisinin Attenuated the Symptoms of Mice Model of Systemic Lupus Erythematosus by Restoring the Treg/Th17 Balance. Clin Exp Pharmacol Physiol (2021) 48(4):626-33. doi: 10.1111/1440-1681.13461

53. Tang J, Yang R, Lv L, Yao A, Pu L, Yin A, et al. Transforming Growth FactorBeta-Expressing Mesenchymal Stem Cells Induce Local Tolerance in a Rat Liver Transplantation Model of Acute Rejection. Stem Cells (2016) 34 (11):2681-92. doi: 10.1002/stem.2437

54. Wang J, Wang G, Sun B, Li H, Mu L, Wang Q, et al. Interleukin-27 Suppresses Experimental Autoimmune Encephalomyelitis During Bone Marrow Stromal Cell Treatment. J Autoimmun (2008) 30(4):222-9. doi: 10.1016/ j.jaut.2007.10.001

55. Gagliani N, Amezcua VM, Iseppon A, Brockmann L, Xu H, Palm NW, et al. Th17 Cells Transdifferentiate Into Regulatory T Cells During Resolution of Inflammation. Nature (2015) 523(7559):221-5. doi: 10.1038/nature14452

56. Brockmann L, Gagliani N, Steglich B, Giannou AD, Kempski J, Pelczar P, et al. IL-10 Receptor Signaling Is Essential for TR1 Cell Function In Vivo. J Immunol (2017) 198(3):1130-41. doi: 10.4049/jimmunol.1601045

57. Dellepiane S, Leventhal JS, Cravedi P. T Cells and Acute Kidney Injury: A Two-Way Relationship. Front Immunol (2020) 11:1546. doi: 10.3389/ fimmu.2020.01546

58. Yang XY, Song J, Hou SK, Fan HJ, Lv Q, Liu ZQ, et al. Ulinastatin Ameliorates Acute Kidney Injury Induced by Crush Syndrome Inflammation by Modulating Th17/Treg Cells. Int Immunopharmacol (2020) 81:106265. doi: 10.1016/j.intimp.2020.106265

59. Kluger MA, Melderis S, Nosko A, Goerke B, Luig M, Meyer MC, et al. Treg17 Cells Are Programmed by Stat 3 to Suppress Th17 Responses in Systemic Lupus. Kidney Int (2016) 89(1):158-66. doi: 10.1038/ki.2015.296

60. Gu Z, Tan W, Ji J, Feng G, Meng Y, Da Z, et al. Rapamycin Reverses the Senescent Phenotype and Improves Immunoregulation of Mesenchymal Stem
Cells From MRL/lpr Mice and Systemic Lupus Erythematosus Patients Through Inhibition of the mTOR Signaling Pathway. Aging (Albany NY) (2016) 8(5):1102-14. doi: 10.18632/aging.100925

61. He Y, Zhou S, Liu H, Shen B, Zhao H, Peng K, et al. Indoleamine 2, 3Dioxgenase Transfected Mesenchymal Stem Cells Induce Kidney Allograft Tolerance by Increasing the Production and Function of Regulatory T Cells. Transplantation (2015) 99(9):1829-38. doi: 10.1097/TP.0000000000000856

62. Ren W, Yin J, Duan J, Liu G, Tan B, Yang G, et al. mTORC1 Signaling and IL17 Expression: Defining Pathways and Possible Therapeutic Targets. Eur J Immunol (2016) 46(2):291-9. doi: 10.1002/eji.201545886

63. Priyadharshini B, Loschi M, Newton RH, Zhang JW, Finn KK, Gerriets VA, et al. Cutting Edge: TGF-Beta and Phosphatidylinositol 3-Kinase Signals Modulate Distinct Metabolism of Regulatory T Cell Subsets. J Immunol (2018) 201(8):2215-9. doi: 10.4049/jimmunol.1800311

64. Terraza-Aguirre C, Campos-Mora M, Elizondo-Vega R, Contreras-Lopez RA, Luz-Crawford P, Jorgensen C, et al. Mechanisms Behind the Immunoregulatory Dialogue Between Mesenchymal Stem Cells and Th17 Cells. Cells (2020) 9(7):1660-80. doi: 10.3390/cells9071660

65. Delisle JS, Giroux M, Boucher G, Landry JR, Hardy MP, Lemieux S, et al. The TGF-Beta-Smad3 Pathway Inhibits CD28-Dependent Cell Growth and Proliferation of CD4 T Cells. Genes Immun (2013) 14(2):115-26. doi: 10.1038/gene.2012.63

66. Bottcher M, Hofmann AD, Bruns H, Haibach M, Loschinski R, Saul D, et al. Mesenchymal Stromal Cells Disrupt mTOR-Signaling and Aerobic Glycolysis During T-Cell Activation. Stem Cells (2016) 34(2):516-21. doi: 10.1002/ stem.2234

67. Chi H. Regulation and Function of mTOR Signalling in T Cell Fate Decisions. Nat Rev Immunol (2012) 12(5):325-38. doi: 10.1038/nri3198

68. Inoki K, Kim J, Guan KL. AMPK and mTOR in Cellular Energy Homeostasis and Drug Targets. Annu Rev Pharmacol Toxicol (2012) 52:381-400. doi: 10.1146/annurev-pharmtox-010611-134537

69. Hellsten Y, Richter EA, Kiens B, Bangsbo J. AMP Deamination and Purine Exchange in Human Skeletal Muscle During and After Intense Exercise. J Physiol (1999) 520 Pt 3:909-20. doi: 10.1111/j.1469-7793.1999.00909.x

70. Sancak Y, Peterson TR, Shaul YD, Lindquist RA, Thoreen CC, Bar-Peled L, et al. The Rag GTPases Bind Raptor and Mediate Amino Acid Signaling to mTORC1. Science (2008) 320(5882):1496-501. doi: 10.1126/science.1157535

71. Schiavinato J, Haddad R, Saldanha-Araujo F, Baiochi J, Araujo AG, Santos SP, et al. TGF-Beta/atRA-Induced Tregs Express a Selected Set of microRNAs Involved in the Repression of Transcripts Related to Th17 Differentiation. Sci Rep (2017) 7(1):3627. doi: 10.1038/s41598-017-03456-8

72. Singh Y, Garden OA, Lang F, Cobb BS. MicroRNA-15b/16 Enhances the Induction of Regulatory T Cells by Regulating the Expression of Rictor and mTOR. J Immunol (2015) 195(12):5667-77. doi: 10.4049/jimmunol. 1401875

73. Pollizzi KN, Waickman AT, Patel CH, Sun IH, Powell JD. Cellular Size as a Means of Tracking mTOR Activity and Cell Fate of CD4+ T Cells Upon Antigen Recognition. PloS One (2015) 10(4):e121710. doi: 10.1371/ journal.pone.0121710

74. Pollizzi KN, Sun IH, Patel CH, Lo YC, Oh MH, Waickman AT, et al. Asymmetric Inheritance of mTORC1 Kinase Activity During Division Dictates CD8(+) T Cell Differentiation. Nat Immunol (2016) 17(6):704-11. doi: 10.1038/ni.3438

75. Chen G, Dong Z, Liu H, Liu Y, Duan S, Liu Y, et al. mTOR Signaling Regulates Protective Activity of Transferred CD4+Foxp3+ T Cells in Repair of Acute Kidney Injury. J Immunol (2016) 197(10):3917-26. doi: 10.4049/ jimmunol.1601251

76. Saleiro D, Platanias LC. Intersection of mTOR and STAT Signaling in Immunity. Trends Immunol (2015) 36(1):21-9. doi: 10.1016/j.it.2014.10.006

77. Thompson PR, Wang D, Wang L, Fulco M, Pediconi N, Zhang D, et al. Regulation of the P300 HAT Domain Via a Novel Activation Loop. Nat Struct Mol Biol (2004) 11(4):308-15. doi: 10.1038/nsmb740

78. McGeachy MJ, Chen Y, Tato CM, Laurence A, Joyce-Shaikh B, Blumenschein WM, et al. The Interleukin 23 Receptor Is Essential for the Terminal Differentiation of Interleukin 17-Producing Effector T Helper Cells In Vivo. Nat Immunol (2009) 10(3):314-24. doi: 10.1038/ni.1698

79. Chapman NM, Chi H. mTOR Links Environmental Signals to T Cell Fate Decisions. Front Immunol (2014) 5:686. doi: 10.3389/fimmu.2014.00686 
80. Yoshimura A, Naka T, Kubo M. SOCS Proteins, Cytokine Signalling and Immune Regulation. Nat Rev Immunol (2007) 7(6):454-65. doi: 10.1038/nri2093

81. Linossi EM, Babon JJ, Hilton DJ, Nicholson SE. Suppression of Cytokine Signaling: The SOCS Perspective. Cytokine Growth Factor Rev (2013) 24 (3):241-8. doi: 10.1016/j.cytogfr.2013.03.005

82. Shan J, Feng L, Sun G, Chen P, Zhou Y, Xia M, et al. Interplay Between mTOR and STAT5 Signaling Modulates the Balance Between Regulatory and Effective T Cells. Immunobiology (2015) 220(4):510-7. doi: 10.1016/ j.imbio.2014.10.020

83. Lu LF, Thai TH, Calado DP, Chaudhry A, Kubo M, Tanaka K, et al. Foxp3Dependent microRNA155 Confers Competitive Fitness to Regulatory T Cells by Targeting SOCS1 Protein. Immunity (2009) 30(1):80-91. doi: 10.1016/ j.immuni.2008.11.010

84. Yao R, Ma YL, Liang W, Li HH, Ma ZJ, Yu X, et al. MicroRNA-155 Modulates Treg and Th17 Cells Differentiation and Th17 Cell Function by Targeting SOCS1. PloS One (2012) 7(10):e46082. doi: 10.1371/journal.pone.0046082

85. Delgoffe GM, Pollizzi KN, Waickman AT, Heikamp E, Meyers DJ, Horton MR, et al. The Kinase mTOR Regulates the Differentiation of Helper T Cells Through the Selective Activation of Signaling by mTORC1 and Mtorc2. Nat Immunol (2011) 12(4):295-303. doi: 10.1038/ni.2005

86. Milner JD, Brenchley JM, Laurence A, Freeman AF, Hill BJ, Elias KM, et al. Impaired $\mathrm{T}(\mathrm{H}) 17$ Cell Differentiation in Subjects With Autosomal Dominant Hyper-IgE Syndrome. Nature (2008) 452(7188):773-6. doi: 10.1038/ nature06764

87. Yang XP, Ghoreschi K, Steward-Tharp SM, Rodriguez-Canales J, Zhu J, Grainger JR, et al. Opposing Regulation of the Locus Encoding IL-17 Through Direct, Reciprocal Actions of STAT3 and STAT5. Nat Immunol (2011) 12(3):247-54. doi: 10.1038/ni.1995

88. Zhang S, Gan X, Qiu J, Ju Z, Gao J, Zhou J, et al. IL-10 Derived From Hepatocarcinoma Cells Improves Human Induced Regulatory $\mathrm{T}$ Cells Function Via JAK1/STAT5 Pathway in Tumor Microenvironment. Mol Immunol (2021) 133:163-72. doi: 10.1016/j.molimm.2021.02.014

89. Mendu SK, Stremska ME, Schappe MS, Moser EK, Krupa JK, Rogers JS, et al. Targeting the Ion Channel TRPM7 Promotes the Thymic Development of
Regulatory T Cells by Promoting IL-2 Signaling. Sci Signal (2020) 13(661): eabb0619. doi: 10.1126/scisignal.abb0619

90. Zhou L, Lopes JE, Chong MM, Ivanov II, Min R, Victora GD, et al. TGF-BetaInduced Foxp3 Inhibits $\mathrm{T}(\mathrm{H}) 17$ Cell Differentiation by Antagonizing RORgammat Function. Nature (2008) 453(7192):236-40. doi: 10.1038/ nature 06878

91. Lohmann S, Eijken M, Moldrup U, Moller BK, Hunter J, Moers C, et al. Ex Vivo Administration of Mesenchymal Stromal Cells in Kidney Grafts Against Ischemia-Reperfusion Injury-Effective Delivery Without Kidney Function Improvement Posttransplant. Transplantation (2021) 105(3):517-28. doi: 10.1097/TP.0000000000003429

92. Zhao Y, Zhu XY, Song T, Zhang L, Eirin A, Conley S, et al. Mesenchymal Stem Cells Protect Renal Tubular Cells Via TSG-6 Regulating Macrophage Function and Phenotype Switching. Am J Physiol Renal Physiol (2021) 320 (3):F454-63. doi: 10.1152/ajprenal.00426.2020

93. Lohmann S, Pool M, Rozenberg KM, Keller AK, Moers C, Moldrup U, et al. Mesenchymal Stromal Cell Treatment of Donor Kidneys During Ex Vivo Normothermic Machine Perfusion: A Porcine Renal Autotransplantation Study. Am J Transplant (2020). doi: 10.1111/ajt.16473

94. Luk F, de Witte SF, Korevaar SS, Roemeling-van RM, Franquesa M, Strini T, et al. Inactivated Mesenchymal Stem Cells Maintain Immunomodulatory Capacity. Stem Cells Dev (2016) 25(18):1342-54. doi: 10.1089/scd.2016.0068

Conflict of Interest: The authors declare that the research was conducted in the absence of any commercial or financial relationships that could be construed as a potential conflict of interest.

Copyright $\odot 2021$ Luo, Guo, Zhang, Cheuk, Jiang, Wang, Xu and Rong. This is an open-access article distributed under the terms of the Creative Commons Attribution License (CC BY). The use, distribution or reproduction in other forums is permitted, provided the original author(s) and the copyright owner(s) are credited and that the original publication in this journal is cited, in accordance with accepted academic practice. No use, distribution or reproduction is permitted which does not comply with these terms. 